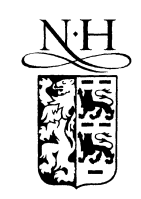

ELSEVIER

\title{
Structure of nanometersized silicon particles prepared by various gas phase processes
}

\author{
H. Hofmeister ${ }^{\text {a,* }}$, P. Ködderitzsch ${ }^{\text {a }}$, J. Dutta ${ }^{b}$ \\ ${ }^{a}$ Max Planck Institute of Microstructure Physics, Weinberg 2, D-06120 Halle (Saale), Germany \\ ${ }^{\mathrm{b}}$ Department of Materials Science, Swiss Federal Institute of Technology, CH-1015 Lausanne, Switzerland
}

\begin{abstract}
We have explored various gas phase processes for the fabrication of nanometersized $\mathrm{Si}$ and $\mathrm{SiO}_{x}$ particles and measured their structural properties (agglomeration, size, shape, crystallinity, surface roughness and internal structure) by conventional and high resolution electron microscopy. Agglomerated amorphous Si particles, $10-30 \mathrm{~nm}$ in size, were prepared by gas phase reactions including cluster growth processes in a low pressure silane plasma. Annealing at $900^{\circ} \mathrm{C}$ resulted in almost complete crystallisation of nearly spherical particles covered by an amorphous oxide shell. Inert gas arc evaporation of silicon yielded single crystalline, spherical Si particles, 4-16 nm in size, in which no defects were detected. These particles, agglomerated into chains and tangles, are covered entirely by a thin amorphous oxide layer. Thermal evaporation of solid $\mathrm{SiO}$ in an inert gas atmosphere produced agglomerated, nearly spherical amorphous $\mathrm{SiO}_{x}$ particles, 8-24 nm in size, with considerable surface roughness. Upon annealing at $900^{\circ} \mathrm{C}$, the formation of 3-6 nm sized Si crystallites in the interior of these particles was observed. (c) 1998 Elsevier Science B.V. All rights reserved.
\end{abstract}

\section{Introduction}

Nanometer sized silicon particles have interesting optoelectronic properties resulting from sizeinduced quantum confinement effects and the presence of $\mathrm{Si}-\mathrm{O}$ bonds at the surface [1-4]. Besides erosive surface techniques applied to compact $\mathrm{Si}$ materials $[5,6]$, there is growing interest in the fabrication of particulate silicon showing comparable properties. By embedding in a passivating matrix, these materials are designed to achieve stability against affects of any ambient conditions. Methods of synthesis applied range from co-sputtering of silicon and silica [7-9] and ion implantation of silicon into silica [10-12] to laser ablation $[13,14]$ and

\footnotetext{
${ }^{*}$ Corresponding author. Tel.: +49-345 558 2677; fax: +49-345 551 1223; e-mail: hof@mpi-halle.mpg.de.
}

gas phase evaporation of silicon [15-17]; as well as plasma-assisted decomposition of silane [18-22]. Investigations of the structure, composition and properties of such materials are directed at the formation of nanometer sized $\mathrm{Si}$ crystallites during synthesis and processing $[7,9,11,17,22]$, to the formation and variation of a silicon oxide surface layer or matrix [14,16,18-20,22] and to the role and nature of $\mathrm{Si}-\mathrm{O}$ bonds in the particle/oxide interface $[8-10,12,17-20]$.

We have used plasma enhanced chemical vapour deposition (PECVD) and inert gas aggregation by an arc evaporator to prepare $\mathrm{Si}$ particles and also thermal evaporation of solid $\mathrm{SiO}$ in an inert gas atmosphere to produce $\mathrm{SiO}_{x}$ particles. The latter method is aimed at combining the relative ease of evaporating $\mathrm{SiO}$ with its tendency to decompose into $\mathrm{Si}$ and $\mathrm{SiO}_{2}$ at elevated temperatures. Structural properties of the prepared 
particulate materials have been studied by conventional and high resolution electron microscopy (HREM), and compared with respect to their possibilities for the fabrication of Si-based materials with interesting optoelectronic properties.

\section{Experimental}

A conventional capacitively coupled radio frequency PECVD system [21,22] was used for decomposition of semiconductor grade silane gas at $0.1 \mathrm{mbar}$ pressure and $30 \mathrm{sccm}$ flow rate at room temperature. Si particles, collected from the reactor, were annealed in forming gas $(92 \%$ nitrogen and $8 \%$ hydrogen) at $300-900^{\circ} \mathrm{C}$. As-prepared and annealed particles were dispersed in propanol and transferred to carbon coated microgrids for electron microscopy inspection.

Arc evaporation of silicon of $5 \mathrm{~N}$ purity (Goodfellow, Cambridge), in an Ar gas atmosphere of about 2 mbar pressure, was achieved by indirectly preheated $\mathrm{Si}$ electrodes powered with short pulses of 60-100 A. Carbon coated microgrids were placed at a distance of about $10 \mathrm{~cm}$ above the arc evaporator to collect particles from the gas stream.

Solid $\mathrm{SiO}$ of $99 \%$ purity (Fluka, Buchs) was evaporated from a resistively heated $\mathrm{Ta}$ boat at nearly $1100^{\circ} \mathrm{C}$ in an $\mathrm{Ar}$ gas atmosphere at about 2 mbar pressure. The particles were collected on carbon coated microgrids, as described above, and were annealed subsequently in forming gas at $900^{\circ} \mathrm{C}$.

Structural measurements of the various particulates was carried out using a conventional transmission electron microscope (JEM 100C) operating at $100 \mathrm{kV}$ and a high resolution electron microscope (JEM 4000EX) operating at $400 \mathrm{kV}$. HREM images were recorded using optimal imaging conditions (near Scherzer focus) and were subjected to digital image processing for contrast enhancement.

\section{Results}

By the plasma induced decomposition of silane under the conditions explained elsewhere [23], Si

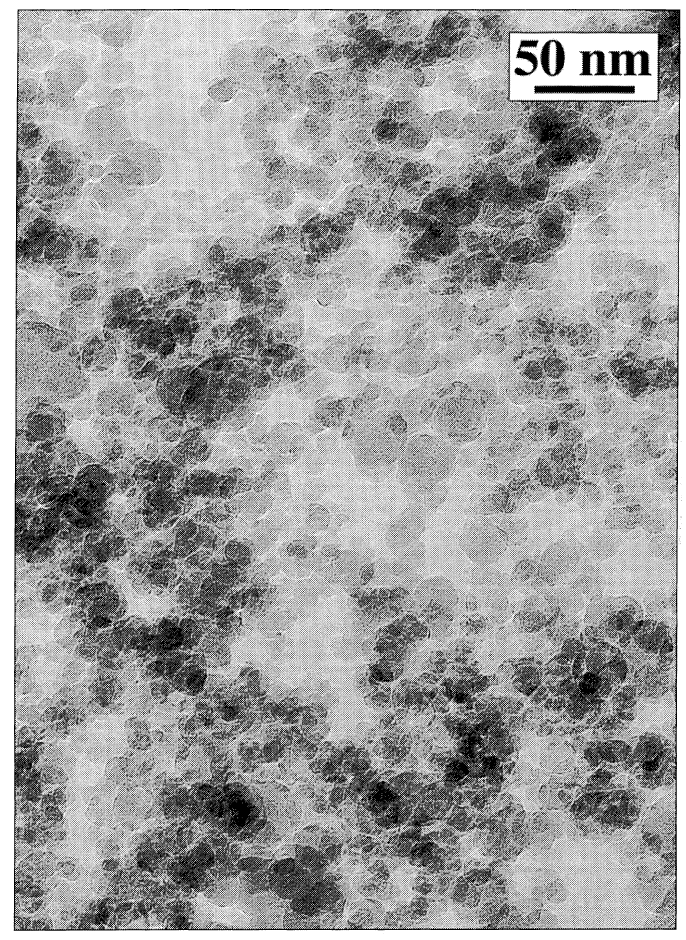

Fig. 1. Agglomerated Si particles deposited by PECVD.

particles of 10-30 nm size were obtained in an agglomerated state, as shown in Fig. 1. In the interior of these amorphous particles, ring-like contrast features (shown in Fig. 2(a)) are observed upon annealing. Fivefold twinned structures, as shown in Fig. 2(b), appear at $700^{\circ} \mathrm{C}$ among the first crystalline regions. Almost complete crystallisation of the particles was achieved by annealing at $900^{\circ} \mathrm{C}$. The interior of these particles, covered by an amorphous oxide layer of about $1 \mathrm{~nm}$ thickness as shown in Fig. 2(c), exhibits many lattice defects such as stacking faults and twin boundaries.

Arc evaporation of silicon in an argon atmosphere of about 2 mbar yielded spherical particles of $4-16 \mathrm{~nm}$ in size that are agglomerated into chain-like structures as shown in Fig. 3. The perfect single-crystalline nature of diamond cubic lattice type of these particles is illustrated by the HREM image shown in Fig. 4. The Si particles are covered entirely by an amorphous oxide shell of about $1 \mathrm{~nm}$ thickness by which they cohere loosely. 

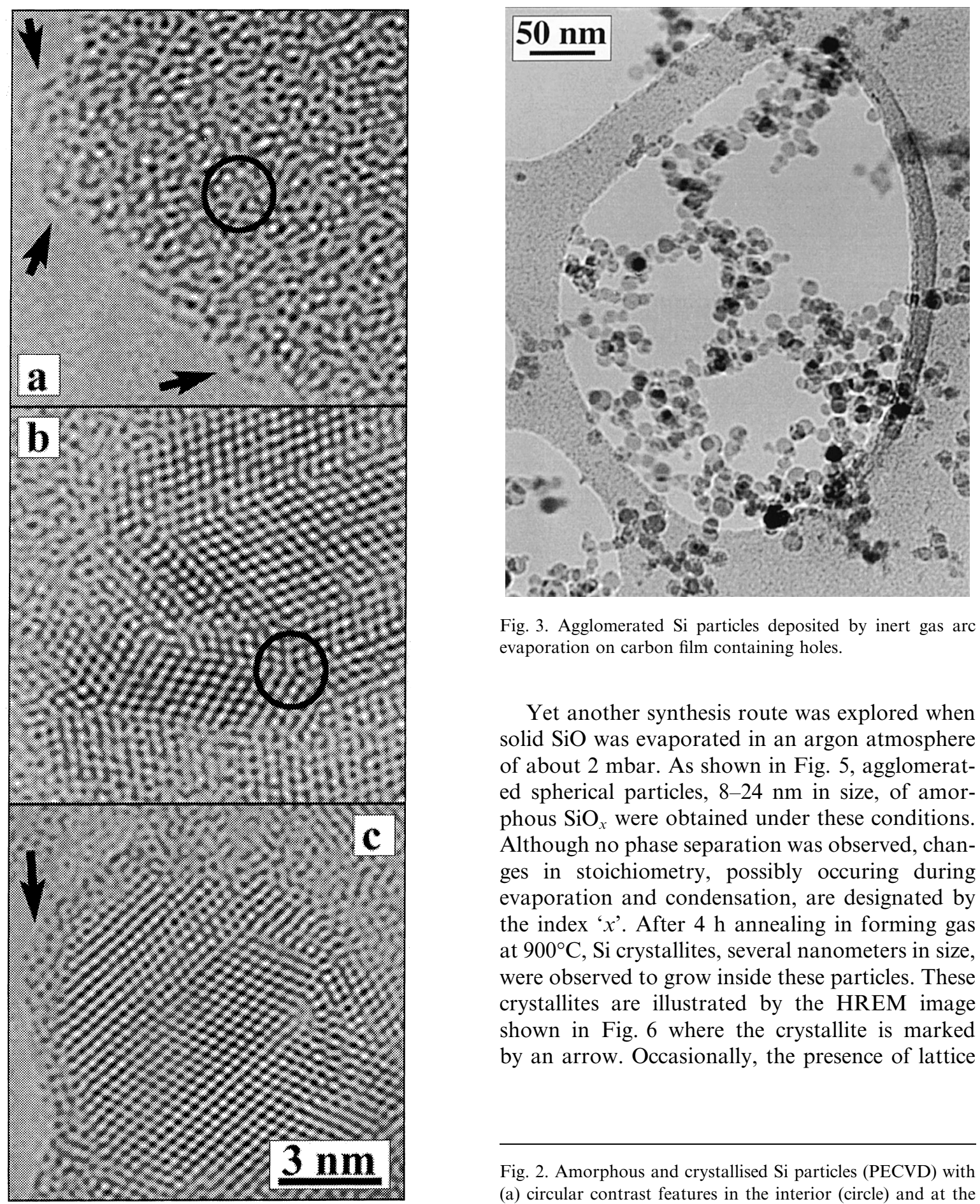

Fig. 3. Agglomerated Si particles deposited by inert gas arc evaporation on carbon film containing holes.

Yet another synthesis route was explored when solid $\mathrm{SiO}$ was evaporated in an argon atmosphere of about 2 mbar. As shown in Fig. 5, agglomerated spherical particles, $8-24 \mathrm{~nm}$ in size, of amorphous $\mathrm{SiO}_{x}$ were obtained under these conditions. Although no phase separation was observed, changes in stoichiometry, possibly occuring during evaporation and condensation, are designated by the index ' $x$ '. After $4 \mathrm{~h}$ annealing in forming gas at $900^{\circ} \mathrm{C}, \mathrm{Si}$ crystallites, several nanometers in size, were observed to grow inside these particles. These crystallites are illustrated by the HREM image shown in Fig. 6 where the crystallite is marked by an arrow. Occasionally, the presence of lattice

Fig. 2. Amorphous and crystallised Si particles (PECVD) with (a) circular contrast features in the interior (circle) and at the surface (arrow) after $1 \mathrm{~h}$ at $300^{\circ} \mathrm{C}$; (b) fivefold twinned structure (circle) after $1 \mathrm{~h}$ at $700^{\circ} \mathrm{C}$; and (c) amorphous oxide surface layer (arrow) after $3.5 \mathrm{~h}$ at $800^{\circ} \mathrm{C}$. 


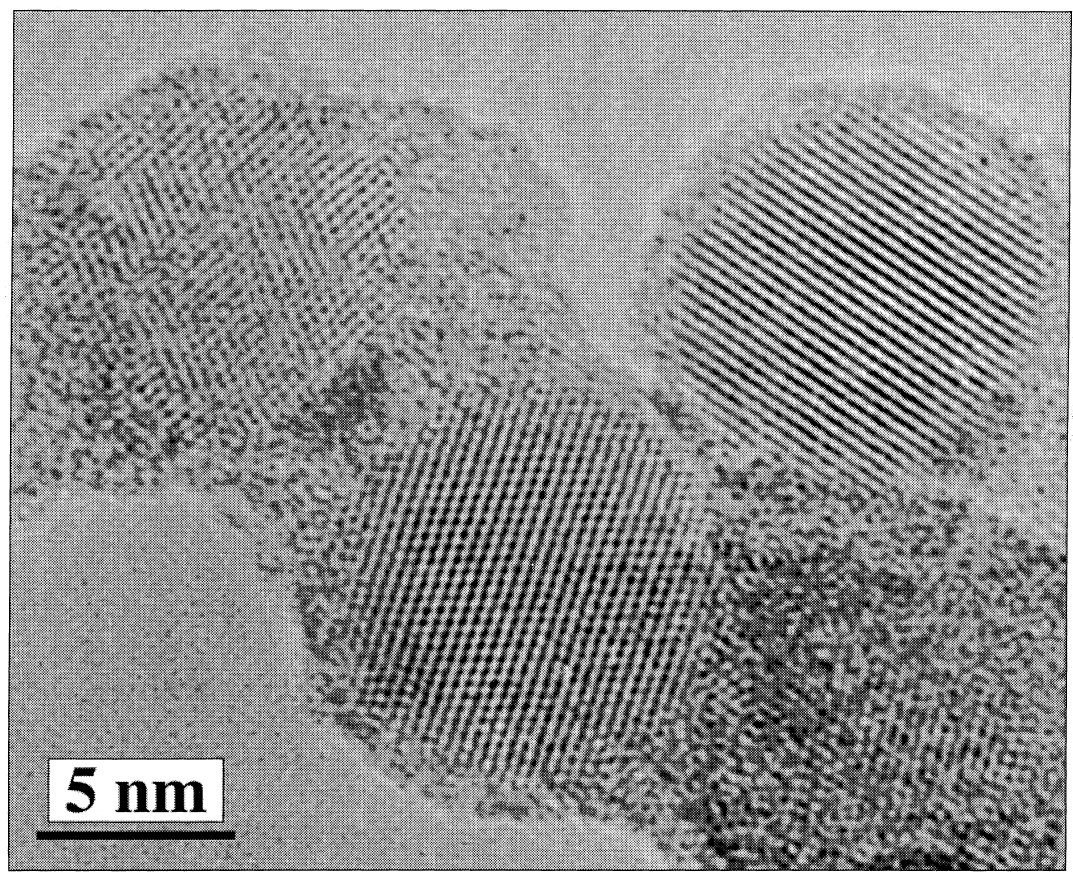

Fig. 4. Defect-free Si particles (inert gas arc evaporation) entirely covered by an amorphous oxide layer.

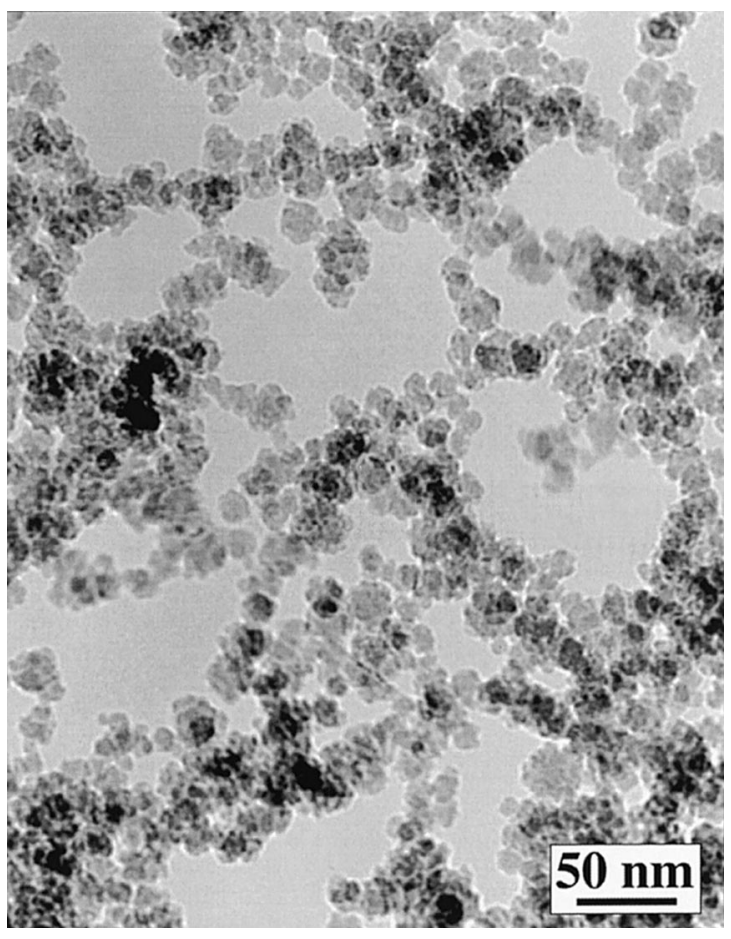

Fig. 5. Agglomerated $\mathrm{SiO}_{x}$ particles deposited by inert gas evaporation of solid $\mathrm{SiO}$ on carbon film containing holes. defects such as twin boundaries is observed in these crystallites.

\section{Discussion}

Here we shall briefly discuss the structural characteristics of the various particulate materials and the relationship to the details of their formation. The structure and crystallisation behaviour of the CVD synthesized particles obviously is affected by $\mathrm{Si}$ clusters formed in the plasma [24]. This effect is indicated by ring-like contrast inhomogeneities of the amorphous particle as well as by fivefold twinned structures with non-crystallographic symmetries that occur with the onset of crystallisation. Image contrast calculations for cluster models with inherent fivefold symmetries [25] supports the above interpretation. The defect structure of the nearly completely crystallised particles is mainly caused by non-correlated growth twinning events that are characteristic of the solid phase crystallisation of silicon and germanium [21,22]. 


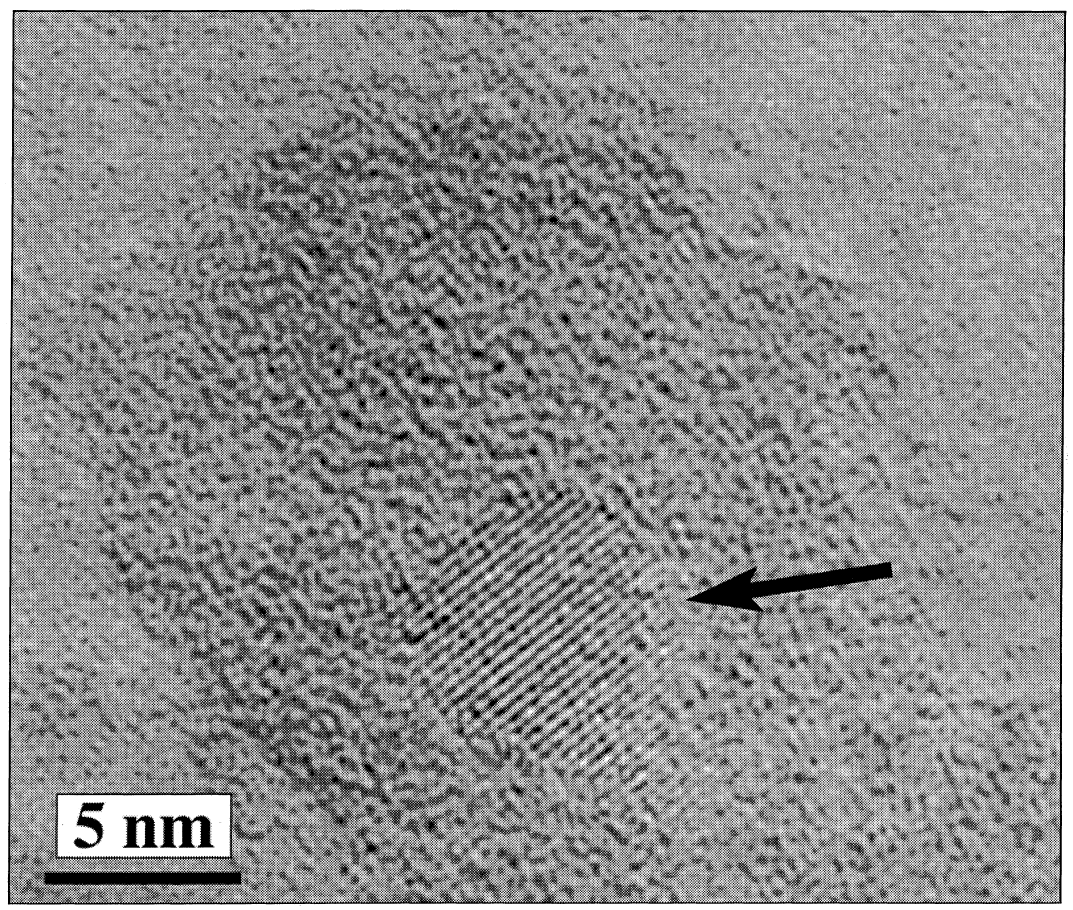

Fig. 6. Si crystallite (marked by arrow) formed within an amorphous $\mathrm{SiO}_{x}$ particle after annealing for $4 \mathrm{~h}$ in forming gas.

The absence of any lattice defects such as twin boundaries in the particles obtained by inert gas arc evaporation, points to the formation and crystallisation by rapid cooling of liquid droplets homogeneously condensed in a supersaturated vapour. Obviously, the supersaturation achieved by the arc plasma is high enough to enable such processes without the additional cooling of the Ar gas as required for thermal evaporation of silicon [26]. The amorphous oxide layer surrounding the particles presumably result from small quantities of oxygen present in the residual gas during formation and increases upon exposure to the ambient environment. The rough oxide surface favours agglomeration of the particles without coalescence or sintering processes.

Inert gas evaporation of $\mathrm{SiO}$ proves to be an effective method for producing silicon oxide particulate materials. Annealing at $900^{\circ} \mathrm{C}$ does not alter the size, shape and agglomeration of the particles. Electron diffraction analysis, however, indicates distinct changes in local composition and ordering of the material before the appearance of the first $\mathrm{Si}$ crystallites. The decomposition of $\mathrm{SiO}_{x}$, which according to the random bond model [27], has a random distribution of tetrahedrally coordinated $\mathrm{Si}-$ $\left(\mathrm{Si}_{y} \mathrm{O}_{4-y}\right)$ with $0 \leqslant y \leqslant 4$, may be interpreted in terms of a phase separation which leads to regions of different composition of $\mathrm{SiO}_{x}$ with $0 \leqslant x \ll 1$ and $1 \ll x \leqslant 2$, respectively. Solid phase crystallization taking place in silicon-rich regions at sufficient size and temperature may result in the formation of characteristic twin defects [21,22].

\section{Conclusions}

In a comparative study we have prepared nanometer sized Si particles surrounded by oxide phases with various configurations. The results indicate that gas phase processes are well suited to produce Si particulates having the structural properties required for interesting optoelectronic properties. In particular, by synthesis and processing of Si suboxide particles, there is a potential for the fabrication of structured Si-based materials. Efforts are 
now in progress to pursue these routes in more detail to optimize the properties of such materials.

\section{References}

[1] L.T. Canham, Appl. Phys. Lett. 57 (1990) 1046.

[2] V. Lehmann, U. Gösele, Appl. Phys. Lett. 58 (1991) 856.

[3] A. Bsiesy, Y.F. Nicolau, A. Ermolief, F. Muller, F. Gaspard, Thin Solid Films 255 (1995) 43.

[4] H. Tamura, M. Rückschloss, T. Virschem, S. Veprek, Thin Solid Films 255 (1995) 92.

[5] U. Gösele, V. Lehmann, Mater. Chem. Phys. 40 (1995) 253.

[6] M.H. Ludwig, A. Augustin, R.E. Hummel, T. Gross, J. Appl. Phys. 80 (1996) 5318.

[7] I.T.H. Chang, F. Niu, D. Slimovici, C. Wildig, P.A. Leigh, P.J. Dobson, B. Cantor, Mater. Sci. Forum 225-227 (1996) 175.

[8] M. Zacharias, D. Dimova-Malinovska, M. Stutzmann, Philos. Mag. B 73 (1996) 799.

[9] V.G. Baru, A.P. Chernushich, V.A. Luzanov, G.V. Stepanov, L.Yu. Zakharov, V.G. O’Dannel, I.V. Bradley, N.N. Melnik, Appl. Phys. Lett. 69 (1996) 4148.

[10] K.S. Min, K.V. Shcheglov, C.M. Yang, H.A. Atwater, M.L. Brongersma, A. Polman, Appl. Phys. Lett. 69 (1996) 2033.

[11] T. Komoda, J. Weber, K.P. Homewood, P.L.F. Hemment, B.J. Sealy, Nucl. Instrum. and Meth. B 120 (1996) 93.

[12] T. Shimizu-Iwayama, S. Nakao, K. Saitoh, Nucl. Instrum. and Meth. B 120 (1996) 97.
[13] I.A. Movtchan, R.W. Dreyfus, W. Marine, M. Sentis, M. Autric, G. Le Lay, N. Merk, Thin Solid Films 255 (1995) 286.

[14] W. Marine, I. Mochtvan, A. Simakine, L. Patrone, R. Dreyfus, M. Sentis, M. Autric, N. Merk, Mater. Res. Soc. Symp. Proc. 397 (1996) 3654.

[15] H. Morisaki, F.W. Ping, H. Ono, K. Yazawa, J. Appl. Phys. 70 (1991) 1869.

[16] S. Sato, H. Ono, S. Nozaki, H. Morisaki, Nanostruct. Mater. 5 (1995) 589.

[17] L.N. Dihn, Phys. Rev. B 54 (1996) 5029.

[18] A.J. Kenyon, P.F. Trwoga, C.W. Pitt, J. Appl. Phys. 79 (1996) 9291.

[19] W. Calleja, C. Falcony, A. Torres, M. Aceves, R. Osorio, Thin Solid Films 270 (1996) 114.

[20] K. Kim, M.S. Suh, T.S. Kim, C.J. Youn, E.K. Suh, Y.J. Shin, K.B. Lee, H.J. Lee, M.H. An, H.J. Lee, H. Ryu, Appl. Phys. Lett. 69 (1996) 3908.

[21] H. Hofmeister, T. Junghanns, J. Non-Cryst. Solids $192 \& 193$ (1995) 550

[22] H. Hofmeister, J. Dutta, H. Hofmann, Phys. Rev. B 54 (1996) 2856.

[23] J. Dutta, R. Houriet, H. Hofmann, J.-L. Dorier, A.A. Howling, C. Hollenstein, in: H.J. Mathieu, B. Reihl, D. Briggs (Eds.), Proceedings of the ECASIA 1995, Wiley, New York, 1996, p. 483.

[24] J. Dutta, R. Houriet, H. Hofmann, H. Hofmeister, Nanostruct. Mater. 9 (1997) 359.

[25] H. Hofmeister, Phys. Bl. 53 (1997) 37.

[26] H. Hofmeister, P. Ködderitzsch, U. Gösele, Ber. Bunsenges. Phys. Chem. 101 (1997) 1647.

[27] H.R. Phillipp, J. Phys. Chem. Solids 32 (1971) 1935. 